\section{PROSE: A simple user-oriented program for computer constructed narratives}

\author{
JAMES H. JOHNSON, EARL B. COLE, \\ and THOMAS A. WILLIAMS
}

\section{VA Hospital and Department of Psychiatry, University of Utah Salt Lake City, Utah 84113}

Lanyon (1972) noted the inefficient collection of data by mental health services. He suggested the use of objective (self-report and technician administered) methods of data collection. However, he did not propose an efficient method to utilize this information. Craig, Golenzer, and Laska (1968) and Laska, Morrill, Kline et al. (1967) developed computerized programs called SCRIBE and NOVEL which make objective data useful by constructing narratives from them. The purpose of this paper is to describe a program called PROSE (Production of Records by On-line System Editing) that constructs narratives from objective data and, moreover, is usable by psychologists who are not familiar with programming languages. It was constructed to correct some of the problems posed by NOVEL and SCRIBE.

NOVEL is a free standing program written in machine language for an IBM 360 and its operating system. As such, it is not readily exportable. Furthermore, NOVEL makes use of commands, functions, and input card structure which demand the use of an experienced programmer. Thus, it is difficult for the mental health professional to utilize.

PROSE is a document gencrator program that is written in FORTRAN. It was developed on a CDC 3200 but could easily be used on other systems. PROSE is user-oriented. It is presently being used by mental health professionals and secretaries. Input is in a relatively free form and retains the global structure of the document. Output can be composed at a key punch without the aid of coding sheets. It has branching capabilities, can add or delete output passages, and produces text in publishable format with margin justification, page size, line spacing, paragraph identation, and text compaction. Thus, while PROSE has all of the features necessary for document generation, it does not have the drawbacks associated with the more complicated programs. PROSE is machine independent and is easily used by those without special computer skills.

Using PROSE. There are several basic steps required for the use of PROSE. First, a shect for interviewer rating or a self-report questionnaire must be chosen. Figure 1 shows an example of a rating sheet which is completed by an interviewer and serves as a base for utilizing PROSE.

Second, a skeletal narrative report is devcloped from the rating sheet. An example is shown in Figure 2 . The blanks (insertion points) are left for individual patient data.

Third, a PROSE narrative is keypunched. This has the same format as the above but includes certain program commands. The insertions of data in the text are indicated by an * followed by a number $(* 2)$. This is the insertion point number (IPN). Figure 3 shows an example of the key-punched narrative.

Fourth, insertion material is defined and key punched. This material is related to the text through IPNs. Where special text is to be inserted, it is indicated by an IPN followed by a $\$$ followed by the associated answer shect number and its related text (*2 \$1 Single). Where free-form material (names, etc.) are to be

The authors thank Mr. Kenneth Hayes for his support and encouragement and Mr. Thomas Cook for assuming programming and documentation responsibility for the PROSE program.

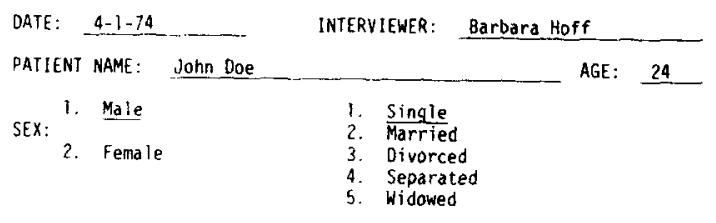

RATE THE FOLLOWJW INTERVIEN BEHAVIORS

1. Inappropriate appearance and/or behavior?

$\begin{array}{llll}\text { A. Posturing? } & \text { 1. Yes 2. No } \\ \text { B. Silliness? } & \text { 1. Yes } 2 \text {. No } \\ \text { C. Agitation? } & \text { 1. Yes } 2 \text {. No } \\ \text { D. Orientation? } & \text { T. Time } & \text { 2. Place } & \text { 3. Person } \\ \text { E. Cooperative during evaluation? } & \text { 1. Yes } & \text { 2. No }\end{array}$

Figure 1. Patient input questionnaire.

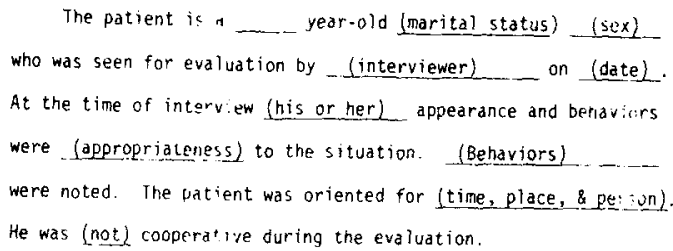

Figure 2. Mental status exam.

\footnotetext{
The patient is a*1. year-old *2*3 who was seen for evaluation on $* 4$ by $* 5$. At the time of interview *6 appearance and behavior were *? to the situation. $* 8 * 9 * 10$ were noted. The patient was oriented for *i2 $* 13 * 14$. He was *15 cooperative during the evaluation.
}

Figure 3. PROSE narrative; text with insertion points.

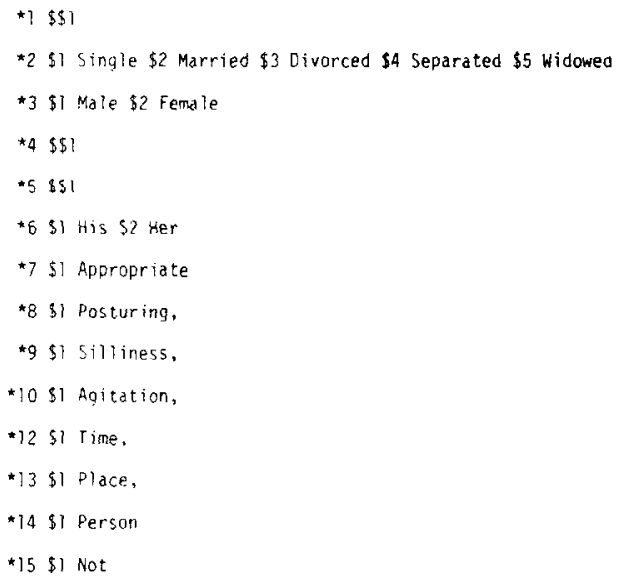

Figure 4. Insertions.

entered into the text, and IPN is followed by $\$ \$$ and a number $(* 1 \$ \$ 1)$. An example of the insertion input is shown in Figure 4.

Figure 5 shows an example of the printed report that is generated. It is indented for paragraphs and presents a text compacted for casy reability. 